\title{
Surface Modification of Ceramic Nanophosphors by Atmospheric Pressure Plasma
}

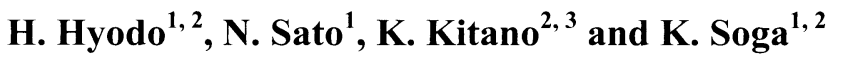 \\ ${ }^{1}$ Department of Materials Science and Technology, Tokyo University of Science, \\ 2641 Yamazaki, Noda, Chiba 278-8510, Japan \\ ${ }^{2}$ Polyscale Technology Research Center, Tokyo University of Science, \\ 2641 Yamazaki, Noda, Chiba 278-8510, Japan \\ ${ }^{3}$ Center for Atomic and Molecular Technologies, Graduate School of Engineering, \\ Osaka University, Yamada-oka 2-1, Suita, Osaka 565-0871, Japan
}

\begin{abstract}
Rare-earth doped yttrium oxide $\left(\mathrm{Y}_{2} \mathrm{O}_{3}\right)$ is a good candidate to be used for the near infrared (NIR) fluorescence bioimaging. Coating of $\mathrm{Y}_{2} \mathrm{O}_{3}$ nanoparticles with polymer is one of the key issues to use $\mathrm{Y}_{2} \mathrm{O}_{3}$ nanoparticles as a fluorescent probe for the NIR fluorescence bioimaging. We developed a plasma fluidized bed for homogeneously exposing nanoparticles to the atmospheric plasma, which is expected to enhance chemical reactions in a system involving organic materials. Poly(acrylic acid) (PAAc) modified $\mathrm{Y}_{2} \mathrm{O}_{3}$ was exposed to the atmospheric plasma by using the bed. Improved acid durability and dispersion stability was observed after plasma treatment. These improvements do not correspond to thermal reaction of intra-reaction in PAAc chain, but can be assigned to a chelation reaction between $\mathrm{Y}^{3+}$ on the $\mathrm{Y}_{2} \mathrm{O}_{3}$ particles surface and $\mathrm{COO}^{-}$groups in PAAc chain.
\end{abstract}

Keywords: atmospheric pressure plasma, surface modification, nanoparticle, poly(acrylic acid)

\section{Introduction}

Fluorescence bioimaging (FBI) is one of the most important methods for biology and medicine to visualize biological phenomena. Rare-earth doped ceramic nanophosphors (RED-CNP) are known to emit efficient near infrared (NIR) fluorescence in the wavelength region between 800 and $2000 \mathrm{~nm}$ under NIR excitation. The NIR-FBI, by using RED-CNP, is now attracting increasing interest since current problems of the FBI, such as color fading, photo damage to objects, autofluorescence and scattering, can be avoided by the use of the NIR [1-12]. The main advantage of the NIR-FBI is the low optical scattering due to the long wavelength, which results in deep penetration depth of both excitation and emission lights to enable imaging of the target inside living bodies. Rare-earth doped $\mathrm{Y}_{2} \mathrm{O}_{3}$ nanoparticles (NPs) are good candidate for RED-CNP to be used for the

\section{NIR-FBI.}

However, $\mathrm{Y}_{2} \mathrm{O}_{3}$ NPs without any surface modification can easily be dissolved in acidic water [13], which may limit the use of them for the FBI. Improvement of chemical durability of the $\mathrm{Y}_{2} \mathrm{O}_{3}$ NPs is one of the key issues to use $\mathrm{Y}_{2} \mathrm{O}_{3}$ NPs as a fluorescent probe in NIR-FBI. Coating of $\mathrm{Y}_{2} \mathrm{O}_{3}$ NPs with polymer can possibly avoid the dissolution of the $\mathrm{Y}_{2} \mathrm{O}_{3}$ NPs under acidic conditions [14]. Surface modification of $\mathrm{Y}_{2} \mathrm{O}_{3}$ NPs is also important to improve the dispersion stability [6].

Recently, we have successfully been employing atmospheric pressure plasma (e.g., LF-plasma jet) for the property improvement of $\mathrm{Y}_{2} \mathrm{O}_{3} \mathrm{NPs}$. LF plasma jet can be generated by the application of low frequency (LF) pulsed high voltage $(\sim 10 \mathrm{kV}$, $10 \mathrm{kHz}$ ) to $\mathrm{He}$ gas flow $[15,16]$. In the system, plasma jet is generated with a single powered 
electrode and a dielectric tube for He gas. Since plasma jet provides highly reactive species in gas and liquid, it can initiate or drive chemical reactions upon the surface of solid material and inside the liquid solution. Moreover its gas temperature is close to room temperature, and kinetic energies of species are quite low because of frequent collisions of species at atmospheric pressure. Therefore the atmospheric pressure plasma is as an appropriate agent for reformulation of polymer under atmospheric pressure [17-18]. However, the LF-plasma jet system is not adequate to homogeneously expose NPs into atmospheric plasma for a treatment.

The objective of this study is to develop a plasma fluidized bed for homogeneously exposing ceramic NPs to atmospheric pressure plasma as well as the evaluation of the plasma treatment effects on polymer-coated RED-CNP as an NIR-FBI probe. Poly(acrylic acid) (PAAc) modified $\mathrm{Y}_{2} \mathrm{O}_{3} \quad \mathrm{NPs} \quad\left(\mathrm{PAAc}-\mathrm{Y}_{2} \mathrm{O}_{3} \quad \mathrm{NPs}\right)$ as RED-CNP were exposed to the atmospheric plasma by using the bed. The effects of the plasma treatment on acid durability and dispersion stability were evaluated.

\section{Experiments}

2.1 Synthesis of rare-earth doped $\mathrm{Y}_{2} \mathrm{O}_{3} \mathrm{NPs}$

Erbium and Ytterbium ion-codoped $\mathrm{Y}_{2} \mathrm{O}_{3}$ $\left(\mathrm{Y}_{2} \mathrm{O}_{3}: \mathrm{Er}, \mathrm{Yb}\right)$ NPs were synthesized by the homogeneous precipitation method [19]. To obtain the precursors, $\mathrm{CO}\left(\mathrm{NH}_{2}\right)_{2}(0.8 \mathrm{~mol}), \mathrm{Y}\left(\mathrm{NO}_{3}\right)_{3}$. $6 \mathrm{H}_{2} \mathrm{O}(9.6 \mathrm{mmol}), \mathrm{Er}\left(\mathrm{NO}_{3}\right)_{3} \cdot 5 \mathrm{H}_{2} \mathrm{O}(0.2 \mathrm{mmol})$ and $\mathrm{Yb}\left(\mathrm{NO}_{3}\right)_{3} \cdot \mathrm{nH}_{2} \mathrm{O}(0.2 \mathrm{mmol})$ were dissolved in $100 \mathrm{~mL}$ of distilled water. The aqueous solution was heated at $90{ }^{\circ} \mathrm{C}$ and stirred for $1 \mathrm{~h}$. The obtained precipitates were freeze dried for $48 \mathrm{~h}$. Then, $\mathrm{Y}_{2} \mathrm{O}_{3}$ :Er, $\mathrm{Yb}$ NPs was synthesized by the heat treatment of the precursors at $900{ }^{\circ} \mathrm{C}$ for 30 min using the electric furnace Synthesis of $\mathrm{Y}_{2} \mathrm{O}_{3}: \mathrm{Er}$, Yb NPs was confirmed by FE-SEM observation, $\mathrm{XRD}$ and fluorescence measurement.

\subsection{Preparation of PAAc modified $\mathrm{Y}_{2} \mathrm{O}_{3}: \mathrm{Er}, \mathrm{Yb}$ $\left(\mathrm{Y}_{2} \mathrm{O}_{3}\right.$-PAAc) NPs}

The surface of $\mathrm{Y}_{2} \mathrm{O}_{3}$ NPs was at first modified with PAAc in an aqueous solution. $\mathrm{Y}_{2} \mathrm{O}_{3}: \mathrm{Er}, \mathrm{Yb}$ NPs (100 mg) and sodium polyacrylate (Mw: 5100) $(1 \mathrm{~g})$ were dispersed in $100 \mathrm{~mL}$ of distilled water and stirred for $1 \mathrm{~h}$ at room temperature. The free excess polymer in the solution was removed by ultracentrifugation $(21000 \mathrm{G}, 20 \mathrm{~min}, 3$ times). $\mathrm{Y}_{2} \mathrm{O}_{3}$-PAAc NPs were prepared by freeze drying of

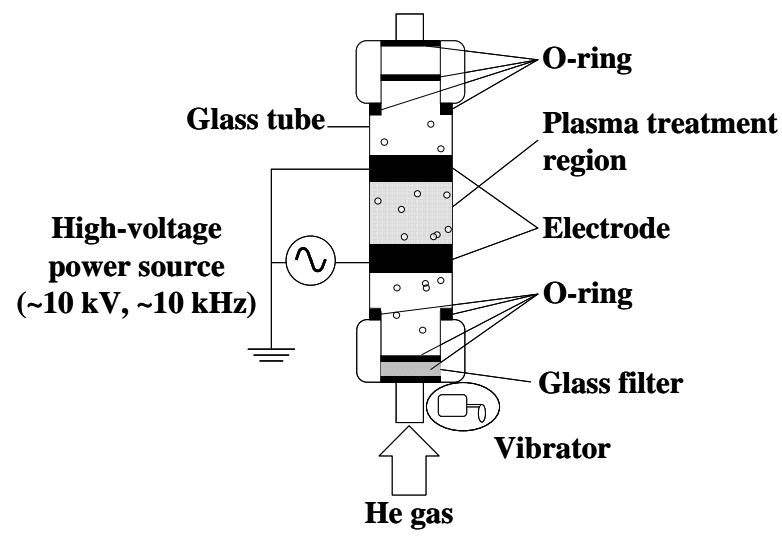

Fig. 1 Schematic illustration of plasma fluidized bed for ceramics nanoparticles.

the obtained particles for $48 \mathrm{~h}$. PAAc modification was confirmed by FT-IR measurement.

\subsection{Plasma fluidized bed and plasma treatment}

Figure 1 shows a schematic illustration of plasma processing device for the reforming of polymer on the surface of ceramics NPs. We used a glass tube (outside diameter $\times$ height: $\phi 40 \times 120$ $\mathrm{mm}$ ) both as a dielectric barrier of discharge and a transparent vessel tube to observe the inner condition. A glass filter (pore size: $40-50 \mu \mathrm{m}$ ) was placed in front of the feed port to uniform He gas flow. A vibrator for the glass tube was used to avoid the adhesion of ceramics NPs and to keep the nanoparticles fluidizing. An O-ring for air tight was set between the glass tube and the cap to prevent the contamination from air. A pair of conductive adhesive copper tapes were attached on the outside of the glass tube as electrodes. The power supply system was LHV-13AC (LOGY Electric Co., Ltd). The plasma was generated by the application of $\sim 10 \mathrm{kV}$ and $\sim 10 \mathrm{kHz}$ voltage pulses to the electrode with He gas (99.999\% purity) flowing at a rate of $5 \mathrm{~L} / \mathrm{min}$.

$\mathrm{Y}_{2} \mathrm{O}_{3}$-PAAc NPs were set on the bed and $\mathrm{He}$ gas was introduced into the device. Fluidized $\mathrm{Y}_{2} \mathrm{O}_{3}$-PAAc NPs were exposed to atmospheric plasma for $40 \mathrm{~min}$.

\subsection{Characterization of plasma treated $\mathrm{Y}_{2} \mathrm{O}_{3}$-PAAc NPs}

$\mathrm{Y}_{2} \mathrm{O}_{3}$-PAAc NPs $(40 \mathrm{mg}$ ) were suspended in 40 $\mathrm{mL}$ of distilled water with $\mathrm{HCl}(1 \mathrm{M}, 200 \mu \mathrm{L})$ The time change of $\mathrm{pH}$ of this suspension was measured by $\mathrm{pH}$ meter to examine the chemical durability.

Plasma treated $\mathrm{Y}_{2} \mathrm{O}_{3}$-PAAc NPs were suspended in Tris- $\mathrm{HCl}$ buffer $(10 \mathrm{mM}, \mathrm{pH}=7.4,150 \mathrm{mM}$ $\mathrm{NaCl})(1 \mathrm{mg} / \mathrm{mL})$. The dispersion stability of plasma treated $\mathrm{Y}_{2} \mathrm{O}_{3}$-PAAc NPs was evaluated by 
measuring the solution turbidity with time at a wavelength of $550 \mathrm{~nm}$ using UV-Vis spectrometer (V-630, JASCO). Particle size distribution was measured for the same suspension by DLS (LB-550, HORIBA). Particle size was also measured by FE-SEM (S-4200, HITACHI).

\section{Results and Discussion}

Figure 2 shows the results of the acid durability test of $\mathrm{Y}_{2} \mathrm{O}_{3}$ NPs, $\mathrm{Y}_{2} \mathrm{O}_{3}$-PAAc NPs and plasma treated $\mathrm{Y}_{2} \mathrm{O}_{3}$-PAAc NPs. Here, $\mathrm{Y}_{2} \mathrm{O}_{3}$ NPs are known to dissolve in an acidic solution under $\mathrm{pH}$ less than 6.4 [13]. Accordingly, the $\mathrm{pH}$ of $\mathrm{Y}_{2} \mathrm{O}_{3}$ NPs suspension reaches around 6.4 in minutes due to the dissolution of the $\mathrm{Y}_{2} \mathrm{O}_{3}$ NPs. As for $\mathrm{Y}_{2} \mathrm{O}_{3}$-PAAc NPs, although the $\mathrm{pH}$ change is delayed by the PAAc modification, still it dissolved in several tens minutes. On the other hand, the $\mathrm{pH}$ almost did not change for plasma treated $\mathrm{Y}_{2} \mathrm{O}_{3}$-PAAc NPs with elapsed time up to $4 \mathrm{hrs}$. The acid durability of $\mathrm{Y}_{2} \mathrm{O}_{3}$-PAAc NPs was drastically improved by the plasma treatment. This result indicates that the plasma treatment effectively changed the surface property of the NPs.

Figure 3 shows transient turbidity of the $\mathrm{Y}_{2} \mathrm{O}_{3}$-PAAc NPs suspensions $(1.0 \mathrm{mg} / \mathrm{mL})$ before and after plasma treatment in Tris- $\mathrm{HCl}$ buffer for evaluating the dispersion stability of the NPs. The sediment of the $\mathrm{Y}_{2} \mathrm{O}_{3}$ NPs without PAAc modification was too quick to measure. The $\mathrm{Y}_{2} \mathrm{O}_{3}$-PAAc NPs without plasma treatment starts to settle down approximately in $20 \mathrm{~min}$. This result suggests that the PAAc might be eventually detached from the surface of the $\mathrm{Y}_{2} \mathrm{O}_{3}$ NPs to cause agglomeration in ionic solution. Meanwhile, the sediment of the $\mathrm{Y}_{2} \mathrm{O}_{3}$-PAAc NPs with plasma treatment is much slower due to the sustained

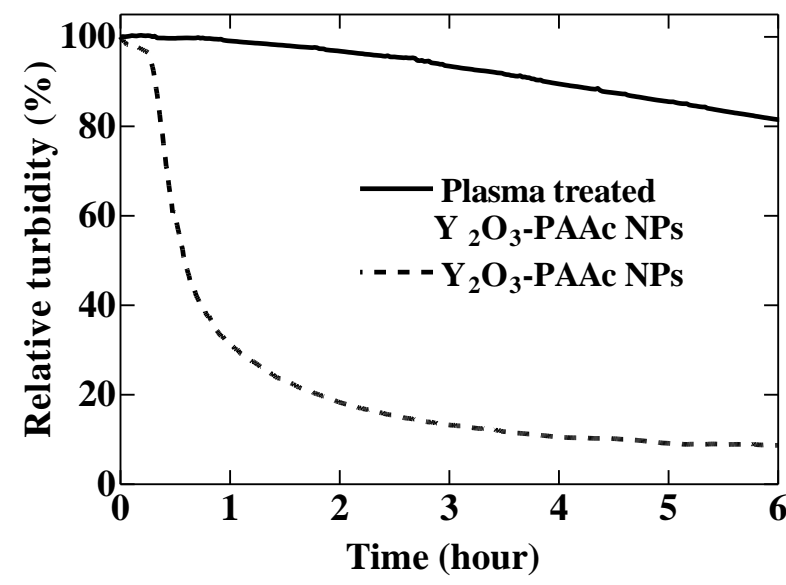

Fig. 2 Transient $\mathrm{pH}$ changes of the particle suspension of $\mathrm{Y}_{2} \mathrm{O}_{3}$ NPs, $\mathrm{Y}_{2} \mathrm{O}_{3}$-PAAc NPs and plasma treated $\mathrm{Y}_{2} \mathrm{O}_{3}$-PAAc NPs after adding $\mathrm{HCl}$. dispersion stability to keep the small particle size by the PAAc on the surface of the $\mathrm{Y}_{2} \mathrm{O}_{3}$ NPs.

The prolonged dispersion by the PAAc modification even without plasma treatment suggests an incomplete electrostatic interaction between the PAAc and $\mathrm{Y}_{2} \mathrm{O}_{3}$. Since the PAAc is partly attaching on the surface of the $\mathrm{Y}_{2} \mathrm{O}_{3} \mathrm{NPs}$, a part of the PAAc can come out from the surface of the $\mathrm{Y}_{2} \mathrm{O}_{3}$ NPs to give steric repulsion since the PAAc is hydrophilic polymer. However, without the steric repulsion by the PAAc on the surface, the $\mathrm{Y}_{2} \mathrm{O}_{3}$ NPs cannot be kept dispersed in ionic solution since the ions will cancel out the electrostatic repulsion due to the surface charge of the NPs as a reason of the dispersion of ceramic NPs in water solution. In addition, even if the PAAc was successfully introduced on the surface of the NPs, if the bonding formation is incomplete, the PAAc can easily been detached from the surface of the NPs by the attacking of the surrounding ions in ionic solution. The high dispersion stability of the $\mathrm{Y}_{2} \mathrm{O}_{3}$-PAAc NPs after the plasma treatment suggests that the enhancement of the electrostatic interaction, i.e. chelation, between $\mathrm{Y}^{3+}$ on the $\mathrm{Y}_{2} \mathrm{O}_{3}$ particles and $\mathrm{COO}^{-}$group in the PAAc chain to avoid the detachment of the PAAc from the NPs in ionic solution.

Figures 4 and 5 show the particle size distribution obtained from DLS measurement and SEM images of $\mathrm{Y}_{2} \mathrm{O}_{3}$-PAAc NPs before and after plasma treatment, respectively. There was almost no change in the average size and the size distribution by plasma treatment. Because the particle size was almost unchanged by the plasma treatment, the improvements of the acidic

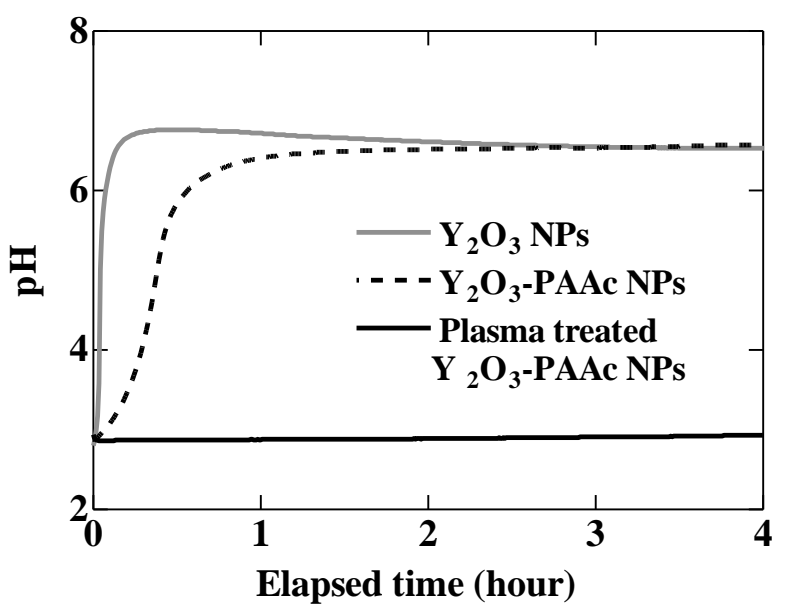

Fig. 3 Transient turbidity of $\mathrm{Y}_{2} \mathrm{O}_{3}$-PAAc NPs (1.0 $\mathrm{mg} / \mathrm{mL}$ ) before and after plasma treatment in Tris- $\mathrm{HCl}$ buffer $(10 \mathrm{mM}, \mathrm{pH}=7.4,150 \mathrm{mM} \mathrm{NaCl})$ for evaluating dispersion stability of the particles. 


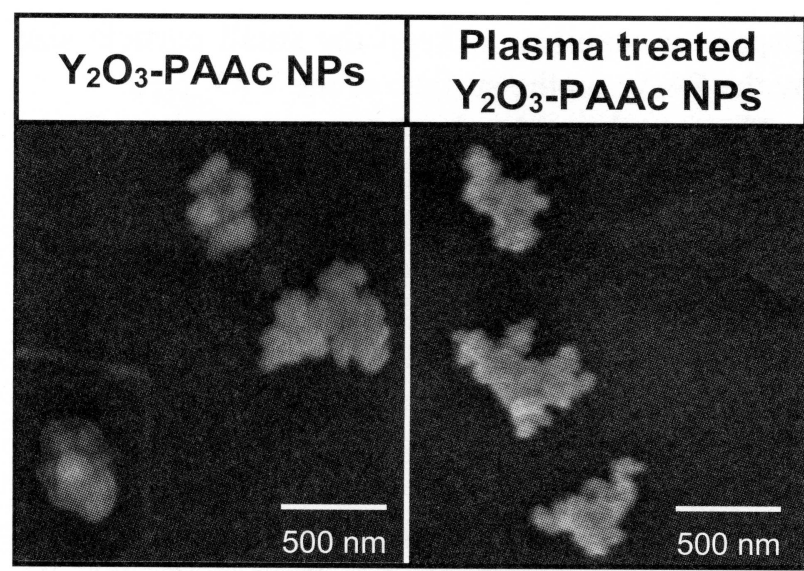

Fig. 4 SEM images of $\mathrm{Y}_{2} \mathrm{O}_{3}$-PAAc NPs before and after plasma treatment.

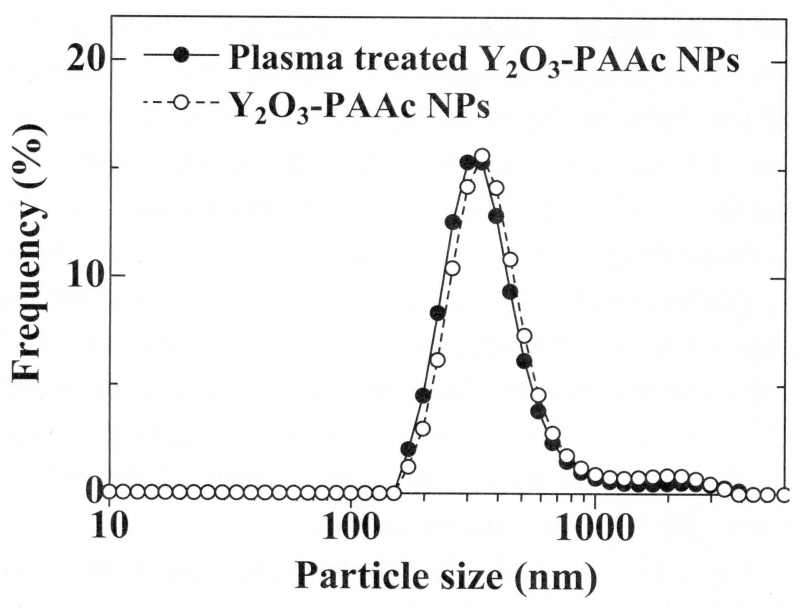

Fig. 5 Particle size distribution of $\mathrm{Y}_{2} \mathrm{O}_{3}$-PAAc NPsin Tris- $\mathrm{HCl}$ buffer $(10 \mathrm{mM}, \mathrm{pH}=7.4,150$ $\mathrm{mM} \mathrm{NaCl}$ ) before and after plasma treatment measured by DLS method.

durability and the dispersion stability are not due to the change of particle size but originated from the change in surface property of the $\mathrm{Y}_{2} \mathrm{O}_{3}$-PAAc NPs.

Focusing onto the reaction of PAAc chain itself, three-steps thermal decomposition is reported for the PAAc [20, 21]. The first step occurs as a reversible dehydration between carboxyl groups at $98{ }^{\circ} \mathrm{C}$. The second and third steps are irreversible reactions to remove $\mathrm{CO}_{2}$ at $284{ }^{\circ} \mathrm{C}$ and $\mathrm{CO}$ at 355 ${ }^{\circ} \mathrm{C}$, respectively, from the polymer chain to make the polymer hydrophobic. Since the first step is reversible reaction in water solution, the improvement of the acid durability cannot be explained by this reaction. The second and third steps should cause hydrophobic surface to the NPs, which in turn causes poor dispersion stability of the particles in water solution. All of the above thermal reactions of PAAc chain itself are not consistent with the improvement of both acid durability and dispersion stability of the NPs. Therefore, the

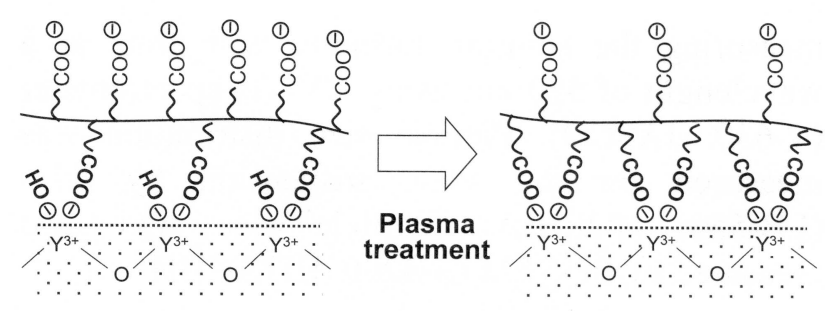

Fig. 6 Schematic illustration of chelation between $\mathrm{Y}^{3+}$ on the $\mathrm{Y}_{2} \mathrm{O}_{3}$ particles surface and $\mathrm{COO}^{-}$groups in PAAc chain.

improved surface properties are not due to the intra-reaction in the PAAc chain, but can be assigned to the enhancement of the chelation between $\mathrm{Y}^{3+}$ on the $\mathrm{Y}_{2} \mathrm{O}_{3}$ particles surface and $\mathrm{COO}^{-}$groups in PAAc chain by the plasma treatment.

Figure 6 illustrates the chalating conversion from incomplete electrostatic interaction and complete interaction between PAAc and $\mathrm{Y}_{2} \mathrm{O}_{3}$ NPs . The surface of the $\mathrm{Y}_{2} \mathrm{O}_{3}$ NPs can be covered not only by $\mathrm{COOH}^{-}$from PAAc but also by $\mathrm{OH}^{-}$ group, which weakens the electrostatic interaction between $\mathrm{Y}^{3+}$ on the $\mathrm{Y}_{2} \mathrm{O}_{3}$ particles surface and $\mathrm{COO}^{-}$groups in PAAc chain. It is known that atmospheric plasma enhances chemical reactions $[16,17]$. The atmospheric plasma may enhance the dehydration between $\mathrm{Y}-\mathrm{OH}$ and $\mathrm{COOH}$ to form $\mathrm{Y}-\mathrm{COO}$ chelate bonding.

\section{Conclusion}

A plasma fluidized bed was developed for homogeneously exposing ceramic nanophosphors to atmospheric pressure plasma. The acid durability and dispersion stability of $\mathrm{Y}_{2} \mathrm{O}_{3}$-PAAc NPs were drastically improved by the atmospheric pressure plasma exposure. The improvement was not due to thermal intra-reaction in PAAc chain itself, but to the enhancement of chelation between $\mathrm{Y}^{3+}$ on the $\mathrm{Y}_{2} \mathrm{O}_{3}$ particles and $\mathrm{COO}^{-}$group in the PAAc chain. The atmospheric pressure plasma treatment was found to be a useful method for driving reactions between NPs and polymer on the surface of the NPs.

\section{Acknowledgement}

This work is supported by the Academic Frontier Project for Private Universities: Matching Fund Subsidy from MEXT (Ministry of Education, Culture, Sports, Science and Technology, Japan) 2006-2010.

\section{Reference}

1. T. Zako, H. Hyodo, K. Tsuji, K. Tokuzen, H. 
K ishimoto, M. Ito, K. Kaneko, M. M aeda and K. Soga, J. Nanomater., 2010 (2010) 1.

2. K. Soga, K. Tokuzen, K. Tsuji, T. Yamano, H. Hyodo and H. Kishimoto, Eur. J . Inorg. Chem., 18 (2010) 2673.

3. K. Soga and Y. N agasaki, M arer. Res. Innov., 14 (2010) 51.

4. K. Soga, Bunseki Kagaku, 58 (2009) 461.

5. E. Hemmer, Y. Kohl, V. Colquhoun, H. Thielecke, K. Soga and S. M athu, J. Phys. Chem. B, 114 (2010) 4358.

6. M. Kamimura, D. M iyamoto, Y. Saito, K. Soga and Y. Nagasaki, Langmuir, 24 (2008) 8864.

7. T. Zako, H. Nagata, N. Terada, A. Utsumi, M. Sakono, M. Yohda, H. U eda, K. Soga, M. M aeda, Biochem. Biophys. Res. Commun., 381 (2009) 54.

8. T. Zako, Hiroyasu Nagata, N. Terada, M. Sakono, K. Soga, M. M aeda, J. M ater. Sci., 45 (2008) 5325.

9. M. Kamimura, D. M iyamoto, Y. Saito, K. Soga and Y. Nagasaki, J. Photopolym. Sci. Tech., 21 (2008) 183.

10. K. Soga, T. Tsuji, F. Tashiro, J. Chiba, M. Oishi, K. Yoshimoto, Y. Nagasaki, K. Kitano and $\mathrm{S}$. Hamaguchi, J. Phys. : Conf. Ser., 106 (2008) 012023.

11. T. K onishi, K. Shimizu, Y. Saito and K. Soga, J. Photopolym. Sci. Tech., 20 (2007) 11.
12. T. K onishi, M. Yamada, K. Soga, D. M atsuura and Y. Nagasaki, J. Photopolym. Sci. Tech., 19 (2006) 145.

13. M. Pourbaix, "Atlas of Electrochemical Equilibria in Aqueous Solutions," (NACE International Cebelcor, Houston, Texas, 1974) pp.181.

14. Y. Saito, K. Shimizu, M. Kamimura, H. Furusyo, K. Soga and Y. Nagasaki, Trans. Mater. Res. Soc. J pn., 33 (2006) 803.

15. K. Kitano, H. Furusho, Y. Nagasaki, S. Ikawa and $\mathrm{S}$. Hamaguchi, Proceedings of International Conference on Phenomena in lonized Gases XXVIII (Prague, J uly 2007) 2007, 1131.

16. H. A oki, K. Kitano, S. Hamaguchi, Plasma Sources Technol. 17 (2008) 025006.

17. H. Furusho, K. Kitano, S. Hamaguchi and Y. Nagasaki, Chem. Mater., 21 (2009) 3526.

18. S. I kawa, K. K itano and S. Hamaguchi, Plasma Process. Polym., 7 (2010) 33.

19. N.Venkatachalam, Y. Saito and K. Soga, J. Am. Ceram. Soc., 92 (2009) 1006.

20. R. Koizumi, M. Yamada, K. Soga and Y. Nagasaki, J. Photopolym. Sci. Tech., 18 (2005) 51. 21. J. J. M aurer, D. J. Eustace and C. T. Ratcliffe M acromolecules, 20 (1987) 196. 